\title{
Research on Key Elements of Campus Soccer Development Based on Interpretative Structure Model
}

\author{
Wu Fan, Chen Huan, Zhou Rui \\ Nanchang University College of Science and Technology, Jiangxi, 330029, China
}

Keywords: Campus football; Key influencing factors; Interpretative structural modeling; Means-end chain

\begin{abstract}
This research arranges and selects the Related Influencing Factors (RIFs) of campus soccer development and analyses the relationships between these factors through literature review method and Expels interview method. Drawing lessons from others' experience, constructing model for the RIFs of campus Soccer development based on the Interpretative Structural Modeling in system engineering. And using Means End Chain(MEC) model, the researcher obtains the Key Influencing Factors(KIFs)of campus soccer development which contribute to improve the policy, extent of socialize, executive system, public opinion and educational system of campus soccer. Finally, the focus of this paper is to discuss the lack of campus football socialization problems, and points out the measures to promote the socialization of campus football: actively introduce social capita1. theformation of campus footbal1 assets management companies. and building a campus football match broadcast platform. SO that the parents can take part in the socialize measures of cam pus footbal1.
\end{abstract}

\section{Introduction}

Since the development of campus football in 2009, the relevant scholars on the development of campus football problems endlessly put forward a number of constructive comments and suggestions, simply presented one by one: the establishment and improvement of the campus football four league system; gradually improve the mechanism[1]; improving the administrative management system; to educate the main department of the management[2-3]. The relevant departments attach great importance to the research results and introduce a series of policies to solve the problem of the development of China's campus football, but the policy points to the problem are parallel, there is no focus. China's campus football itself there is human, financial and material resources, the lack of focus on the "Sesame Salt" type of development model is difficult to meet the needs of the campus football tackling work[4-5]. Therefore, we need to explore the key factors to carry out campus football, to achieve from the "exhaustive" to "focus on breakthroughs", from the "structure-led" to "efficiency optimization" concept change, to further improve efficiency[6].

On the whole, the factors that affect the development of football in China can include: the main factors, dominant factors, hidden factors and semi-hidden factors, these factors can be divided into: students participate in the will[7-8]. The attitude of the president, the attitude of the president, the level of coaches, capital investment, site construction, policy implementation system, to carry out campus football goals set, campus football promotion policy, social opinion, campus football level, league system, insurance system, Staff management system, education system construction, teaching and training arrangements, the degree of campus soccer social $\mathrm{J}$, the school community in which the size of the community, the main body of the campus football recognition and loyalty[9]. 


\section{Model Introduction}

\section{Explain the structural model}

The Interpretative Structural Modeling (ISM) is J. N. Wae1d proposed a systematic model for the analysis of complex socio-economic problems in 1973 to analyze the logical relationship between elements of complex systems[10]. This model is mainly used for qualitative analysis, which is conducive to the relationship between visual complex factors. ISM has been proven to be widely used to understand and deal with various types of system problems. It is an effective way to analyze and reveal complex relational structures[11].

\section{The establishment of adjacency matrix}

The relevant factors affecting the development of campus football are marked as, $\mathrm{S}_{1}$, student participation intention; $S_{2}$, participation in the main body of the campus football recognition and loyalty; $S_{3}$, parent attitude; $S_{4}$, principal attitude; $S_{5}$, coach level; $S_{6}$, capital investment; $S_{7}$, site construction; $\mathrm{S}_{8}$, school community site size; $\mathrm{S}_{9}$, policy implementation system; $\mathrm{S}_{10}$, the campus football goals set; $S_{11}$, campus football promotion policy; $S_{12}$, public opinion; $S_{13}$, the campus football culture level; $S_{14}$, league system; $S_{15}$, insurance system perfect; $S_{16}$, trainer management system; $S_{17}$, school protection system construction; $S_{18}$, the campus soccer socialization; $S_{19}$, teaching and training arrangements[12]. According to the correlation between the relevant factors, according to the following rules fill in the relevant factors shown in Table 1 table.

\section{Build a reachable matrix}

The reachable matrix is a matrix that reflects the degree to which a vertex of a directed graph can be reached by a certain path. It is obtained by adding the adjacency matrix A to the unit matrix I (except that the elements on the main diagonal are $(0+0=0,0+1=1,1+1=1 ; 0 \times 0=0,0 \times 1=0$, $1 \times 1=1$ ), then the Boolean elements, until the matrices of the two adjacent powers are equal. The lowest of the equal matrices is the reachable matrix M, shown as Figure 1.

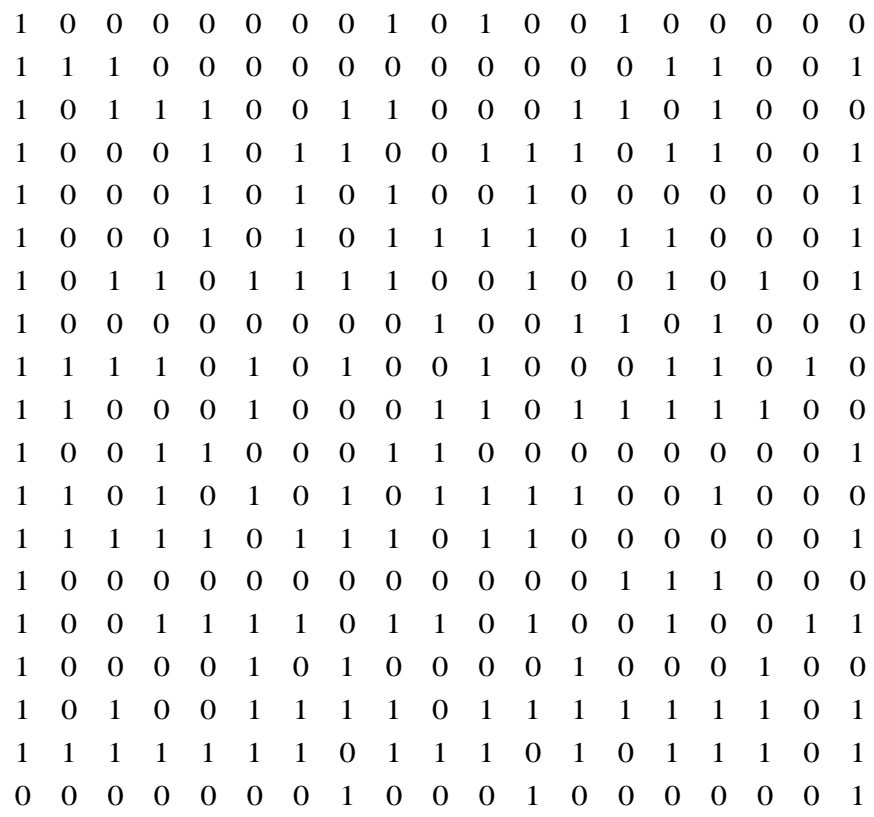

Figure 1. Relevant influencing factors reachable matrix

\section{Interpretation of structural model analysis}

There are many factors related to the development of campus football in our country. The above 19 RIFs are the most influential factors in the selection of the problem. The specific impact on the development of campus football has been discussed in the existing research at home and abroad. The innovation of this research is to sum up these influencing factors and establish the hierarchical, 
visualized and clear explanatory structural model according to the relationship among the factors. The structural model is analyzed as follows:

(1) It can be seen from Figure 2 that the most influential factors influencing the goal of campus football development are student participation intention, capital investment, soccer field construction, campus football culture construction, league system, learning and training arrangement, coaches Level, they are affected by the third layer of factors, the first three factors must also be through them to achieve the ultimate goal. The most fundamental factor is the degree of campus soccer socialization and the campus football promotion policy, this layer is by the external factors (social level) and internal factors (to promote the policy) on the campus football force.

(2) The second and third tier of factors in the development of campus football is the direct impact of factors and the basis of factors, play a role, indispensable. This two-tier influencing factors directly determine whether the internal and external factors of campus football can effectively promote the development of campus football.

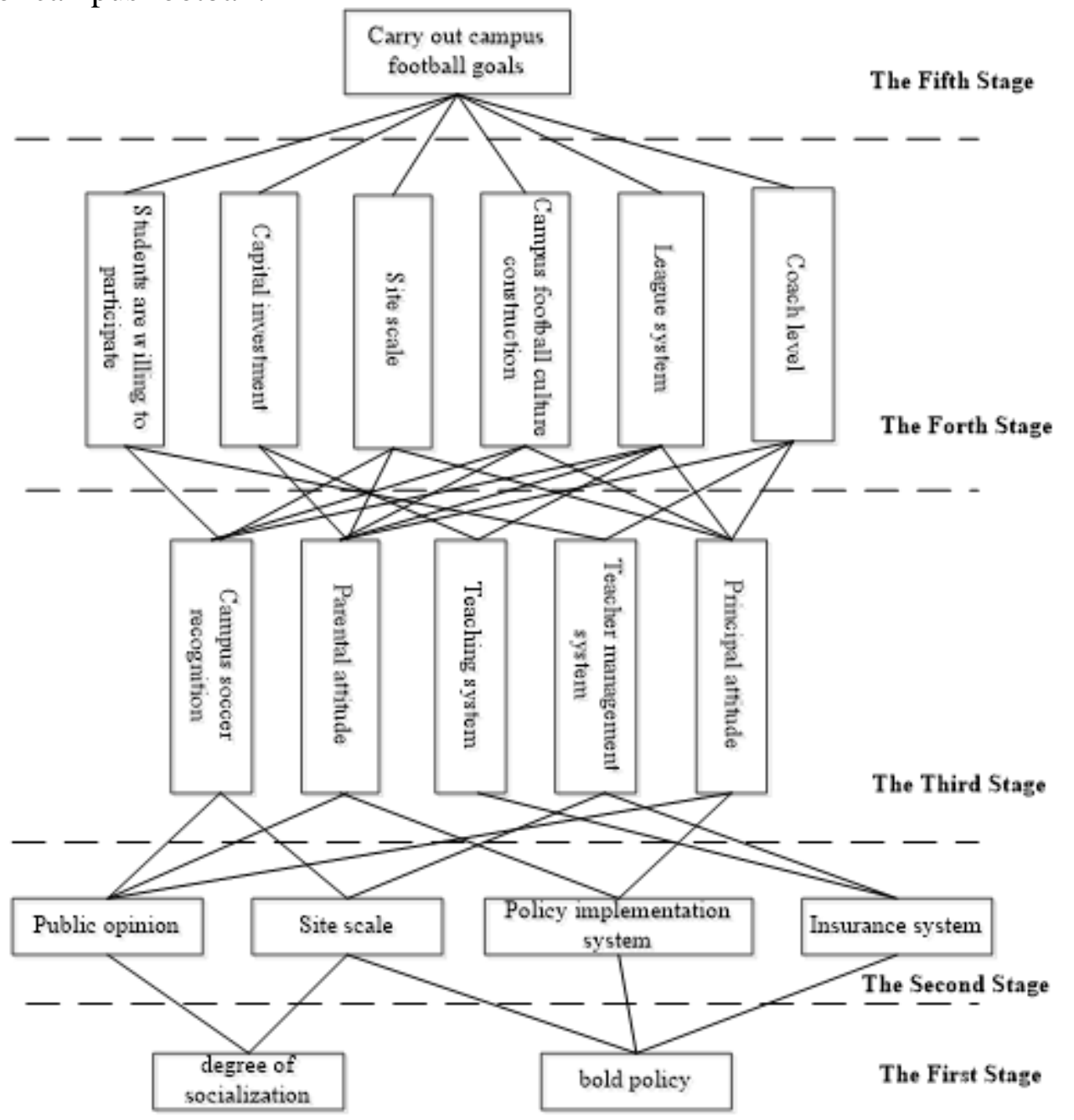

Figure 2. Explain of the structural model

\section{Identification of the key influencing factors}

The root cause of the development of things, not outside the things but in the inside of things, anything inside the kind of contradiction. But we can not look at all the contradictions in the process, we must distinguish between the primary and secondary categories, focusing on seizing the main contradictions. The key factor in the development of campus football is that we should focus on grasping the main contradictions among the many contradictions in the development of campus football. To find out and grasp these main contradictions, all the problems are solved.

The key factors of the analysis, many scholars with Delphi method or fuzzy comprehensive evaluation method, and these methods subjective strong, limited credibility, this paper intends to use 
a more objective and more logical means of the purpose of chain, that is, Purpose 1, through the means 2; if 2 is not yet available, it can be seen as a new purpose 3; to achieve the purpose of 3, through the means 4 , if 4 is not yet available, but also as a new purpose 5 ; to achieve the purpose of 5 , the demand to achieve means 6 ; if 6 has been obtained, then the purpose of 1 can be gradually reached. In this case, 6-5-4-3-2-1 formed a chain of means.

It can be seen from Table 1 that the key influencing factors of the development of campus football in our country are campus football promotion policy, socialization degree, policy enforcement system, social public opinion and schooling mechanism. This study identifies five key factors that affect the development of campus football. So we can focus on the current campus football work as: the improvement of the campus football promotion policy, optimize the policy implementation system, to achieve the education sector as the leading, the sports sector cooperation, the establishment of school protection mechanism, to correct public opinion and improve the degree of socialization of campus football. On the first four schools to carry out the work of football, the existing literature has been a lot of discussion, the relevant policies are gradually improved. And how to improve the socialization of campus football research is relatively lacking, we focus on the campus football to promote the socialization of several measures.

Table 1. Node path number list

\begin{tabular}{|c|c|c|c|c|c|}
\hline RIFs & $\operatorname{step}_{\mathrm{i}}$ & RIFs & step $_{\mathbf{i}}$ & RIFs & step $_{\mathrm{i}}$ \\
\hline $\begin{array}{l}\text { Campus football promotion } \\
\text { policy }\end{array}$ & 30 & Community scale & 9 & Capital investment & 1 \\
\hline Degree of socialization & 24 & Principal attitude & 7 & $\begin{array}{l}\text { Origin } \\
\text { construction }\end{array}$ & 1 \\
\hline $\begin{array}{l}\text { Policy implementation } \\
\text { system }\end{array}$ & 20 & Social identity & 6 & League system & 1 \\
\hline Public opinion & 15 & Parental attitude & 2 & $\begin{array}{l}\text { Campus football } \\
\text { culture }\end{array}$ & 1 \\
\hline Mechanism of study & 13 & $\begin{array}{l}\text { Coaching management } \\
\text { system }\end{array}$ & 1 & School and training & 1 \\
\hline $\begin{array}{l}\text { The perfection of the } \\
\text { insurance system }\end{array}$ & 9 & $\begin{array}{l}\text { Students' willing to } \\
\text { participate }\end{array}$ & 1 & Coach level & 1 \\
\hline
\end{tabular}

\section{Measures to Promote the Socialization of Campus Soccer}

\section{Actively introduce social funds}

Campus sports venues are relatively backward, the fundamental reason is the lack of funds, can not put a lot of special funds for the upgrading of school sports facilities, but the community has a lot of idle funds in the search for investment projects, and the school is a relatively stable, investment guaranteed units, As long as given some preferential policies, give up a few years of land use rights and management rights, you can get ready-made venues, which can effectively solve the problem of lack of campus football. The specific approach is: the layout of the school can cooperate with private investors, the school land use rights and public property in the form of campus football site construction and private enterprises investors signed an agreement to authorize private investors to undertake football field investment, construction and maintenance. After the completion of the stadium, the stadium is owned by the school. Without affecting the normal class of the school students, the private enterprise investors can exercise the right to operate the stadium. Under the supervision of the school authorities, it should allow private investors to charge or sell soccer-related products pay off their investment costs and make a profit. According to the agreement, when the business expires, the course of ownership and management will be owned by the school all.

\section{Set up campus football assets management company}

We mentioned in front of the campus football to be based on the popularity of football to improve the level of football to a certain extent, we can choose a football talent students to form a high level of sports teams. At this time the school should set up a state-owned nature of the campus football assets 
management company. Schools and asset management companies to implement personnel, assets, financial separation, institutions, business independence, independent accounting, independent bear the risk. "Campus football high level sports team" formation of campus football asset management company, to seek market resources, coaches, referees and team leaders, etc. Campus football high level athletes can enter into agreements and contracts with the company in accordance with the "voluntary principle" to get specific economic and policy compensation by participating in the organization and planning of the football match. The company should be committed to improve the campus football four league system, to format a market-based campus football league, to achieve a win-win development of campus football and income part of the supplement to the campus football public finance, to minimize the pressure on the development of campus football to form a set of Continuous operation of the financial system.

\section{Summary}

There are many factors related to the development of campus football in our country. Through the establishment of the structural model, we can make the complicated relations of these factors hierarchical, clear and visual. This paper analyzes the structure model of the campus football and makes the five key influencing factors of the development of campus football in China, and provides the direction for the development of campus soccer in China. At present, the academic community should strengthen the innovation research on the soccer socialization path of campus. Of course, due to the continuous development of campus football, the key factors of different periods may change. Therefore, we should carry out dynamic and continuous research on the key influencing factors of campus football development, and determine the key influencing factors of campus football development in different periods so as to promote the healthy and efficient development of campus football.

\section{References}

[1] Gilbert W D, Trudel P. Learning to coach through experience: Reflection in model youth sport coaches[J]. Journal of teaching in physical education, 2002, 21(1): 16-34.

[2] Lock D, Filo K, Kunkel T, et al. The development of a framework to capture perceptions of sport organizations legitimacy[J]. Journal of Sport Management, 2015, 29(4): 362-379.

[3] Thomas G L, Wilson M R. Introducing children to rugby: Elite coaches' perspectives on positive player development[J]. Qualitative Research in Sport, Exercise and Health, 2014, 6(3): 348-365.

[4] Bush K A, Edwards M B, Jones G J, et al. Service Learning For Social Change: Raising Social Consciousness Among Sport Management Students[J]. Sport Management Education Journal, 2016, 10(2): 127-139.

[5] Mandal A, Deshmukh S G. Vendor selection using interpretive structural modelling (ISM)[J]. International Journal of Operations \& Production Management, 1994, 14(6): 52-59.

[6] Pfohl H C, Gallus P, Thomas D. Interpretive structural modeling of supply chain risks[J]. International Journal of Physical Distribution \& Logistics Management, 2011, 41(9): 839-859.

[7] Harvey S, Cushion C J, Cope E, et al. A season long investigation into coaching behaviours as a function of practice state: the case of three collegiate coaches[J]. Sports coaching review, 2013, 2(1): 13-32.

[8] Ansari M F, Kharb R K, Luthra S, et al. Analysis of barriers to implement solar power installations in India using interpretive structural modeling technique[J]. Renewable and Sustainable Energy Reviews, 2013, 27: 163-174.

[9] Iyer K C, Sagheer M. Hierarchical structuring of PPP risks using interpretative structural modeling[J]. Journal of Construction Engineering and Management, 2009, 136(2): 151-159. 
[10]Mangla S, Madaan J, Sarma P R S, et al. Multi-objective decision modelling using interpretive structural modelling for green supply chains[J]. International Journal of Logistics Systems and Management, 2014, 17(2): 125-142.

[11]Nasim S. Total interpretive structural modeling of continuity and change forces in e-government[J]. Journal of Enterprise Transformation, 2011, 1(2): 147-168.

[12] Sharma B P, Singh M D. Knowledge sharing barriers: An approach of interpretive structural modeling[J]. IUP Journal of Knowledge Management, 2012, 10(3): 35. 